\title{
VLSM, Dynamic Routing, dan Virtual LAN untuk Peningkatan Kemampuan Lanjut Simulasi Jaringan Menggunakan Cisco Packet Tracer bagi Siswa SMK Walisongo Semarang
}

\author{
Febrian Wahyu Christanto ${ }^{1}$, Whisnumurti Adhiwibowo 2 , Atmoko Nugroho 3 \\ 1,2,3 Universitas Semarang \\ Jl. Arteri Soekarno-Hatta Tlogosari, Semarang, Jawa Tengah, Indonesia 50196 \\ ${ }^{1}$ febrian.wahyu.christanto@usm.ac.id \\ 2 whisnu@usm.ac.id \\ 3atmoko@usm.ac.id
}

\begin{abstract}
SMK Walisongo Semarang memiliki dua jurusan yaitu jurusan TKJ (Teknik Komputer dan Jaringan) serta jurusan Teknik Otomotif. Beberapa materi dasar jaringan di jurusan TKJ (Teknik Komputer Jaringan) yang terdapat di mata pelajaran kelas XI menggunakan Cisco Packet Tracer dalam KBM(Kegiatan Belajar Mengajar) yang baru sebatas ke simulasi dan konfigurasi jaringan komputer dasar. Hal ini sangat kurang karena banyak sekali konfigurasi jaringan berbasis Cisco yang perlu dikuasai secara mendalam oleh siswa. Kendala lain yang dialami adalah masih banyak siswa kelas XI di SMK Walisongo Semarang yang belum memahami tentang simulasi dan konfigurasi static routing dan dynamic routing menggunakan Cisco Packet Tracer yang berguna untuk membangun koneksi antar jaringan komputer. Dari program Pengabdian kepada Masyarakat terdahulu yang dilakukan dosen FTIK Universitas Semarang telah diadakan pelatihan simulasi mengenai static routing, maka tim Pengabdian kepada Masyarakat FTIK Universitas Semarang kali ini mengadakan kegiatan dengan metode praktikum mengenai simulasi dan konfigurasi jaringan lanjutan mengenai VLSM, Dynamic Routing, dan virtual LAN menggunakan Cisco Packet Tracer. Hasil yang ingin dicapai adalah diharapkan ada peningkatan kemampuan dan pengetahuan dalam konfigurasi jaringan berbasis Cisco yang lebih baik untuk siswa SMK Walisongo Semarang.
\end{abstract}

Keywords - TKJ SMK Walisongo Semarang, VLSM, Dynamic Routing, Virtual LAN, Cisco

\section{Pendahuluan}

Perkembangan dunia teknologi semakin pesat hingga mencakup segala aspek kehidupan terutama perkembangan komunikasi. Tak terkecuali teknologi jaringan komputer merupakan salah satu cara pondasi penerapan teknologi informasi dan internet yang berkembang dengan cepat. Untuk membangun sebuah jaringan komputer dibutuhkan suatu mekanisme routing yang digunakan untuk mengintegrasikan seluruh komputer dengan tingkat fleksibilitas yang tinggi. Routing merupakan bagian utama dalam memberikan suatu performansi dalam jaringan. Routing adalah proses pencarian dan penentuan jalur dan router merupakan sebuah alat yang digunakan melakukan proses routing tersebut atau dalam artian luas yaitu sebuah alat yang berfungsi untuk menghubungkan jaringan yang berbeda agar bisa melakukan komunikasi antar device di dalam jaringan tersebut. Konfigurasi routing yang kurang optimal dapat menyebabkan masalah yang dapat mengganggu pengiriman data. Masalah terburuk yang dapat terjadi adalah hilangnya informasi penting yang dikirimkan. Gangguan tersebut bisa terjadi karena konfigurasi routing pada router yang kurang optimal, trafik data yang padat, atau putusnya koneksi antar router.

Konfigurasi routing pada router dapat menggunakan static routing atau dynamic routing. Untuk jaringan komputer yang tidak terlalu besar, penggunaan static routing akan lebih menguntungkan karena konfigurasinya tidak terlalu sulit dan tidak memakan banyak sumber daya. Namun, jika digunakan pada jaringan komputer berukuran besar, static routing akan menyulitkan administrator yang bertugas untuk mengatur dan menjaga konfigurasi tabel routing agar komunikasi dalam jaringan tersebut tetap dapat dilakukan. Oleh sebab itu, muncul berbagai jenis dynamic routing protocol untuk melengkapi proses routing pada jaringan secara otomatis, mempermudah konfigurasi koneksi antar jaringan, dan membantu pekerjaan dari administrator jaringan. Dengan banyaknya routing protocol yang ada, masih sedikit pemahaman lebih lanjut dari siswa di SMK Walisongo Semarang dalam melakukan konfigurasi routing terutama untuk dynamic routing.

Keterbatasan alat berupa router dan switch berbasis Cisco adalah suatu halangan untuk siswa dapat mempelajari konfigurasi jaringan komputer berbasis Cisco. Solusi yang 
ditawarkan adalah konfigurasi jaringan komputer menggunakan Cisco Packet Tracer yang merupakan software simulasi yang digunakan untuk membuat simulasi jaringan komputer berbasis Cisco yang mirip dengan konfigurasi pada alat (router dan switch) aslinya. Pengabdian kepada Masyarakat Universitas Semarang yang pernah dilakukan di SMK Walisongo Semarang sebelumnya adalah konfigurasi jaringan komputer dengan membahas tentang static routing dalam jaringan kecil menggunakan Cisco Packet Tracer. Konfigurasi itu saja sebenarnya masih kurang karena siswa perlu pula mempunyai kemampuan untuk konfigurasi dynamic routing untuk jaringan komputer yang lebih besar dan luas.

Dengan permasalahan dan solusi tersebut, maka tim Pengabdian kepada Masyarakat Universitas Semarang kali ini akan melakukan pelatihan konfigurasi jaringan komputer lanjut dengan membahas masalah perhitungan IP dengan metode VLSM (Variable Length Subnet Mask), dynamic routing, dan virtual LAN (Local Area Network) menggunakan Cisco Packet Tracer dengan harapan siswa SMK Walisongo Semarang terutama pada jurusan TKJ (Teknik Komputer Jaringan) mempunyai pengetahuan dan kemampuan yang lebih dalam hal konfigurasi jaringan komputer berbasis Cisco.

\section{TARGET DAN LUARAN}

Berdasarkan informasi terkait permasalahan mitra seperti yang diuraikan sebelumnya, tim pengabdian akan membantu memberikan solusi terhadap permasalahan yang dihadapi. Permasalahan yang dihadapi yaitu siswa SMK Walisongo Semarang belum terbiasa dengan konfigurasi jaringan komunikasi pengembangan jaringan komunikasi lanjut seperti pemecahan alamat IP (Internet Protocol) untuk membangun jaringan komputer yang efisien. Beberapa kendala lainnya adalah tentang kurangnya pendalaman materi tentang konfigurasi router, konfigurasi dynamic routing, dan pembangunan suatu virtual LAN.

Tim pengabdian mencoba menawarkan solusi dengan pelatihan dan praktek secara langsung di sekolah. Solusi yang ditawarkan adalah pelatihan peningkatan keterampilan penggunaan simulasi Cisco Packet Tracer. Fokus pelatihan adalah peningkatan kemampuan dalam pemecahan IP dengan metode VLSM, menghubungkan jaringan komputer dengan dynamic routing, dan membangun suatu virtual LAN.

Cisco Packet Tracer sendiri adalah perangkat lunak yang sudah banyak dipakai di untuk simulasi jaringan berbasis Cisco. Selain itu perangkat lunak ini secara bebas dan gratis dapat diunduh di internet, tetapi memiliki fungsi dan konten yang baik dalam pembelajaran jaringan komputer berbasis Cisco dan yang terpenting bahwa kebutuhan spesifikasi perangkat keras dalam menjalankan aplikasi ini tidaklah terlalu tinggi, karena dapat berjalan pada komputer dengan spesifikasi rendah dengan RAM (Random Access Memory) minimal 512 MB. Hal ini tidak memberatkan dan tidak menjadi kendala bagi siswa SMK Walisongo kelak setelah kegiatan pelatihan berakhir dan dapat berlatih dengan komputer pribadi masing-masing.

Peserta dari kegiatan ini adalah 25 orang siswa jurusan TKJ (Teknik Komputer Jaringan) SMK Walisongo Semarang. Adapun syarat untuk menjadi peserta, seperti yang telah disepakai dengan pihak sekolah sebagai mitra adalah peserta ditunjuk oleh siswa kelas XI jurusan TKJ SMK Walisongo Semarang dan peserta bersedia mengikuti kegiatan selama 1 (satu) hari.

Target yang diharapkan dari kegiatan ini adalah peserta mampu memahami penggunaan simulasi jaringan Cisco Packet Tracer. Evaluasi berupa studi kasus penggunaan aplikasi dalam membuat topologi suatu jaringan komputer. Selain itu peserta mampu memahami perhitungan pemecahan IP menggunakan metode VLSM. Evaluasi berupa latihan soal beserta pemecahannya. Target lainnya adalah peserta mampu membuat konfigurasi antar jaringan menggunakan dynamic routing dan mampu membangun suatu jaringan virtual LAN sederhana.

Luaran yang dihasilkan adalah kemampuan peserta dalam konfigurasi jaringan berbasis Cisco. Penilaian pemahaman peserta diperoleh berdasarkan hasil evaluasi, pretest, dan posttest. Sedangkan capaian luaran dalam program pengabdian ini terdapat di dalam Tabel 1.

TABEL 1. CAPAIAN LUARAN PENGABDIAN

\begin{tabular}{|c|l|c|}
\hline No. & \multicolumn{1}{|c|}{ Jenis Luaran } & $\begin{array}{c}\text { Indikator } \\
\text { Capaian }\end{array}$ \\
\hline 1 & Publikasi ilmiah & Ada \\
\hline 2 & Publikasi pada media & $\begin{array}{c}\text { Ada (Publikasi } \\
\text { Lokal Web } \\
\text { Sekolah) }\end{array}$ \\
\hline 3 & $\begin{array}{l}\text { Peningkatan pemahaman } \\
\text { dan keterampilan }\end{array}$ & Ada \\
\hline 4 & Buku ajar & Ada \\
\hline
\end{tabular}

III. METODE PELAKSANAAN

Metode yang akan dilaksanakan dalam kegiatan ini adalah metode praktikum secara langsung dan metode ceramah. Sebelum dimulai kegiatan praktikum diawali dengan Cisco packet Tracer, pemecahan IP dengan metode VLSM, dynamic routing, serta virtual LAN. Pengenalan digunakan untuk membantu peserta didik dalam memahami materi dan mengoperasikan perangkat lunak Cisco Packet Tracer. Kegiatan pelatihan ini bertempat di Lab. TKJ SMK Walisongo Semarang.

Masing-masing peserta (siswa SMK Walisongo Semarang) menggunakan 1 (satu) unit komputer selama praktek berlangsung. Kegiatan dilaksanakan dalam 1 (satu) hari dengan durasi pelatihan adalah 4 (empat) jam, terdiri dari 10 menit pretest, 30 menit pengenalan Cisco packet Tracer, VLSM, dynamic routing, dan virtual LAN, 180 menit untuk pelatihan inti, 10 menit untuk evaluasi keseluruhan materi, dan 10 menit posttest. 
Adapun pembagian materi pelatihannya dimulai dari Sesi 1 untuk materi pemecahan IP dengan VLSM dan kemudian dilakukan evaluasi. Sesi 2 untuk materi dynamic routing dan kemudian dilakukan evaluasi. Sedangkan pada Sesi 3 untuk materi virtual LAN dan kemudian dilakukan evaluasi.

Evaluasi keberhasilan kegiatan pelatihan ini dilakukan setelah masing-masing pada sesi pelatihan dan pada akhir kegiatan dengan posttest. Setiap sesi pelatihan akan dilakukan evaluasi kemudian dilanjutkan evaluasi materi secara keseluruhan di akhir kegiatan. Indikator keberhasilan kegiatan ini dilihat dari respon positif dari para peserta melalui evaluasi yang diberikan. Evaluasi kegiatan juga dilakukan berupa test yang diisi siswa SMK Walisongo Semarang terkait dengan kegiatan yang telah diikuti.

\section{A. Kelayakan Perguruan Tinggi}

Dalam rangka menyelesaikan kegiatan Pengabdian kepada Mayarakat yang mengambil tema "Peningkatan Kemampuan VLSM, dynamic routing, dan virtual LAN bagi Siswa SMK Walisongo Semarang" ini diperlukan beberapa kepakaran untuk kelayakan pengabdian ini. Kepakaran yang diperlukan adalah antara lain kemampuan instruktur dalam penguasaan Cisco Packet Tracer yang dikuasai oleh Febrian Wahyu Christanto, M.Cs. Sedangkan kepakaran lainnya adalah penguasaan tentang perhitungan pemecahan IP menggunakan metode VLSM (Variabel Length Subnet Mask) dikuasai oleh Whisnumurti Adhiwibowo, M.Kom. Sedangkan penguasaan terhadap virtual LAN (Local Area Network) dikuasai oleh Atmoko Nugroho, M.Eng. Berdasarkan beberapa kepakaran yang dimiliki oleh tim pelaksana dalam kegiatan Pengabdian kepada Masyarakat ini, maka dapat ditarik kesimpulan bahwa tim pengusul layak untuk mengadakan pengabdian ini.

Pengalaman dari tim pelaksana kegiatan ini dalam hal pengabdian kepada masyarakat dan pengajar mata kuliah bidang teknologi informasi menjadi penunjang kelayakan tim pengabdian. Berikut daftar pengalaman pengabdian kepada masyarakat tim pengabdian dalam kurun waktu 5 tahun terakhir seperti yang terdapat dalam Tabel 2 .
Tabel 2. Pengalaman Dalam Kegiatan PKM

\begin{tabular}{|l|c|l|c|}
\hline \multicolumn{1}{|c|}{ Nama } & Tahun & \multicolumn{1}{|c|}{ Nama Kegiatan } & Tempat \\
\hline $\begin{array}{l}\text { Febrian Wahyu } \\
\text { Christanto, M.Cs. }\end{array}$ & 2013 & $\begin{array}{l}\text { Pelatihan Membuat Blog untuk Siswa dan } \\
\text { Guru SMA Al Islam Semarang }\end{array}$ & $\begin{array}{c}\text { Universitas } \\
\text { Semarang }\end{array}$ \\
\cline { 2 - 4 } & 2014 & $\begin{array}{l}\text { Penyebaran Informasi dengan Konten Digital } \\
\text { Menggunakan Smartphone }\end{array}$ & $\begin{array}{c}\text { Universitas } \\
\text { Semarang }\end{array}$ \\
\cline { 2 - 5 } & 2015 & $\begin{array}{l}\text { Penyebaran Informasi dengan Memanfaatkan } \\
\text { Media Jejaring Sosial }\end{array}$ & $\begin{array}{c}\text { Universitas } \\
\text { Semarang }\end{array}$ \\
\cline { 2 - 4 } & 2015 & $\begin{array}{l}\text { Pelatihan Office dan Internet Bagi Staf } \\
\text { Kecamatan Tugu Semarang }\end{array}$ & $\begin{array}{c}\text { Kecamatan Tugu } \\
\text { Semarang }\end{array}$ \\
\cline { 2 - 5 } & 2016 & $\begin{array}{l}\text { Peningkatan Kemampuan Dasar Komputer } \\
\text { Komputer Menggunakan Raspberry Pi bagi } \\
\text { Siswa SMK Telekomunikasi Tunas Harapan }\end{array}$ & $\begin{array}{c}\text { SMK Tunas } \\
\text { Harapan Salatiga }\end{array}$ \\
\hline $\begin{array}{l}\text { Whisnumurti } \\
\text { Adhiwibowo, } \\
\text { M.Kom. }\end{array}$ & 2013 & $\begin{array}{l}\text { Pengenalan Sistem Jaringan Komputer dan } \\
\text { Simulasi Cisco Packet Tracer }\end{array}$ & $\begin{array}{c}\text { Universitas } \\
\text { Semarang }\end{array}$ \\
\cline { 2 - 5 } & 2014 & $\begin{array}{l}\text { Peningkatan Promosi Sekolah dan } \\
\text { Pengelolaannya dengan Media pada SMA Al } \\
\text { Islam Semarang }\end{array}$ & $\begin{array}{c}\text { SMA Al Islam } \\
\text { Semarang }\end{array}$ \\
\hline $\begin{array}{l}\text { Atmoko Nugroho, } \\
\text { M.Eng. }\end{array}$ & - & & \\
\hline
\end{tabular}

Sedangkan pengalaman mengajar tim pengabdian dalam kurun waktu 5 tahun terakhir seperti yang terdapat dalam Tabel 3 berikut.

TABel 3. Pengalaman Mengajar InStruktur

\begin{tabular}{|c|l|l|}
\hline Nama & \multicolumn{1}{|c|}{ Nama Mata Kuliah } & Tempat Mengajar \\
\hline $\begin{array}{c}\text { Febrian Wahyu Christanto, } \\
\text { M.Cs. }\end{array}$ & $\begin{array}{l}\text { 1. Manajemen Jaringan } \\
\text { 2. Komunikasi dan Keamanan Data } \\
\end{array}$ & Universitas \\
3. Jaringan Komputer & \\
\hline $\begin{array}{c}\text { Whisnumurti Adhiwibowo, } \\
\text { M.Kom. }\end{array}$ & $\begin{array}{l}\text { 1. Manajemen Proyek Perangkat Lunak } \\
\text { 2. Jaringan Komputer }\end{array}$ & Universitas \\
& 3. Basis Data & Semarang \\
\hline Atmoko Nugroho, M.Eng. & 1. Mikroprosesor & \\
& 2. Pemrograman Web & Universitas \\
& 3. Jaringan Komputer & Semarang \\
\hline
\end{tabular}

\section{IV.HASIL DAN LUARAN YANG DICAPAI}

\section{A. VLSM (Variable Length Subnet Mask)}

Untuk memperbaiki kinerja jaringan dan efisiensi alamat IP yang menggunakan teknik pemecahan Subnetting, maka tahun 1992 IETF (Internet Engineering Task Force) memperkenalkan suatu teknik pemecahan IP baru yaitu CIDR dan VLSM.

VLSM mirip dengan CIDR (Classless Inter-Domain Routing) hanya berbeda di tujuan teknik ini dipakai. VLSM menggunakan blok alamat IP yang seefisien mungkin, sedangkan CIDR membuat routing table lebih efisien dengan subnet yang sudah ada.

Perhitungan alamat IP versi 4 menggunakan metode VLSM memungkinkan suatu alamat jaringan mempunyai lebih dari satu subnet mask. Hal ini disebut dengan classless. Karena VLSM yang dicari adalah dari kebutuhan jumlah host, maka lebih diperhatikan untuk jumlah bit $\mathbf{0}$ di dalam subnet mask. VLSM support ke berbagai routing protocol seperti RIP, IGRP, EIGRP, OSPF, dan sebagainya. Rumus VLSM terdapat dalam Gambar 1 berikut. 


\section{$\left(2^{\wedge} N\right)-2>=$ Kebutuhan Host}

Gambar 1. Rumus VLSM

Contoh perhitungan dengan metode VLSM adalah terdapat 4 laboratorium komputer untuk sebuah gedung perkantoran. Kebutuhan komputer adalah 40 host untuk lab. 1, 6 host untuk lab. 2, 100 host untuk lab 3, dan 10 host untuk lab. 4. Alamat IP yang digunakan adalah 192.168.20.0 / 24. Tentukan alamat IP yang efisien untuk kebutuhan lab. tersebut!

Jawaban :

Untuk mencari pembagian IP sesuai dengan kasus tersebut, maka diprioritaskan terlebih dahulu dari lab. dengan kebutuhan host terbesar ke lab. dengan kebutuhan host terkecil. Sehingga urutan pembagian IP dimulai dari lab. 3, lab. 1, lab. 4, dan lab. 6 .

- Lab. 3 (kebutuhan 100 host)

$$
\begin{aligned}
2^{\wedge} n-2> & =100 \\
2^{\wedge} 7-2> & =100 \\
128-2> & =100
\end{aligned}
$$

1) Dari perhitungan tersebut, maka diketahui terdapat 7 bit $\mathbf{0}$ di dalam subnet mask. Subnet mask untuk kebutuhan Lab. 3 adalah 11111111. 11111111. 11111111. 10000000 atau 255.255.255.128.

2) Prefiks untuk kebutuhan Lab. 3 menjadi / 25.

3) Range IP untuk Lab. 3 terdapat dalam Tabel 4.

TABEL 4. RANGE IP LAB. 3

\begin{tabular}{|c|c|c|}
\hline \hline Net ID & Range IP & Broadcast ID \\
\hline 192.168 .20 .0 & $192.168 .20 .1-192.168 .20 .126$ & 192.168 .20 .127 \\
\hline \hline
\end{tabular}

- Lab. 1 (kebutuhan 40 host)

$$
\begin{gathered}
2^{\wedge} n-2>=40 \\
2^{\wedge} 6-2>=40 \\
64-2>=40
\end{gathered}
$$

1) Dari perhitungan tersebut, maka diketahui terdapat $\mathbf{6}$ bit $\mathbf{0}$ di dalam subnet mask. Subnet mask untuk kebutuhan Lab. 1 adalah 11111111. 11111111. 11111111. 11000000 atau 255.255.255.192.

2) Prefiks untuk kebutuhan Lab. 1 menjadi / 26.

3) Range IP untuk Lab. 1 terdapat dalam Tabel 5.

TABEL 5. RANGE IP LAB. 1

\begin{tabular}{|c|c|c|}
\hline \hline Net ID & Range IP & Broadcast ID \\
\hline 192.168 .20 .128 & $192.168 .20 .129-192.168 .20 .190$ & 192.168 .20 .191 \\
\hline \hline
\end{tabular}

- Lab. 4 (kebutuhan 10 host)

$$
\begin{gathered}
2^{\wedge}-2>=10 \\
2^{\wedge} 4-2>=10 \\
16-2>=10
\end{gathered}
$$

1) Dari perhitungan tersebut, maka diketahui terdapat 4 bit $\mathbf{0}$ di dalam subnet mask. Subnet mask untuk kebutuhan Lab. 4 adalah 11111111. 11111111. 11111111. 11110000 atau 255.255.255.240.

2) Prefiks untuk kebutuhan Lab. 4 menjadi / 28.

3) Range IP untuk Lab. 4 terdapat dalam Tabel 6.

TABEL 6. RANGE IP LAB. 4

\begin{tabular}{||c|c|c|}
\hline \hline Net ID & Range IP & Broadcast ID \\
\hline 192.168 .20 .192 & $192.168 .20 .193-192.168 .20 .206$ & 192.168 .20 .207 \\
\hline \hline
\end{tabular}

- Lab. 2 (kebutuhan 6 host)

$$
\begin{gathered}
2^{\wedge} n-2>=6 \\
2^{\wedge} 3-2>=6 \\
8-2>=6
\end{gathered}
$$

1) Dari perhitungan tersebut, maka diketahui terdapat $\mathbf{3}$ bit 0 di dalam subnet mask. Subnet mask untuk kebutuhan Lab. 2 adalah 11111111. 11111111. 11111111. 11111000 atau 255.255.255.248.

2) Prefiks untuk kebutuhan Lab. 2 menjadi / 29.

3) Range IP untuk Lab. 2 terdapat dalam Tabel 7.

TABEL 7. RANGE IP LAB. 2

\begin{tabular}{||c|c|c|}
\hline \hline Net ID & Range IP & Broadcast ID \\
\hline 192.168 .20 .208 & $192.168 .20 .209-192.168 .20 .214$ & 192.168 .20 .215 \\
\hline
\end{tabular}

- $\quad$ Masih tersisa 39 alamat IP yang dapat digunakan untuk pengembangan jaringan ke depan dengan alamat jaringan dimulai dari alamat 192.168.20.216.

\section{B. Dynamic Routing}

Dynamic routing yang digunakan di dalam program pengabdian ini adalah RIP (Routing Information Protocol).

RIP adalah protocol routing dinamis yang digunakan dalam jaringan LAN dan WAN. Protokol ini menggunakan algoritma Distance-Vector Routing, protokol ini mampu membuat tabel routing sendiri, sehingga memudahkan administrator dalam konfigurasi routing di dalam jaringan.

RIP mempunyai 2 (dua) versi yaitu RIP versi 1 dan RIP versi 2. RIP versi 1 bersifat classful dan tidak didukung oleh VLSM. RIP versi 1 tidak didukung pula dengan otentifikasi router sehingga rentan terhadap serangan di dalam jaringan. RIP versi 2 bersifat classless dan didukung oleh VLSM serta CIDR. RIP versi 2 hadir untuk mengatasi kekurangan RIP versi 1. Topologi jaringan pada kegiatan pengabdian ini terdapat dalam Gambar 2.

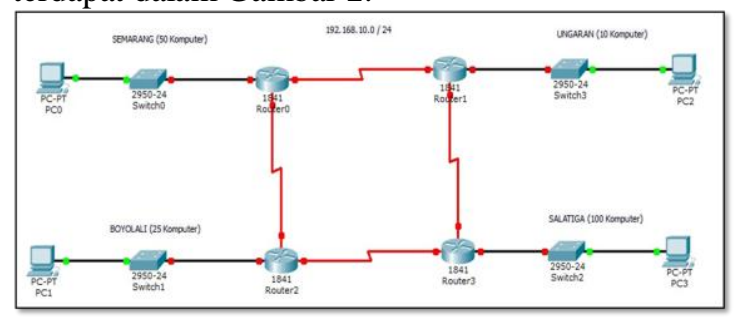

Gambar 2. Topologi Jaringan RIP

Setelah semua titik dalam Gambar 2 diberi IP, maka langkah selanjutnya adalah konfigurasi RIP v2 pada setiap 
kurang mengerti dengan metode VLSM. Pada materi dynamic routing, $66,7 \%$ atau \pm 17 peserta mampu menghubungkan jaringan komputer yang dibangun dengan konfigurasi dynamic routing dan $29,2 \%$ atau \pm 8 peserta mengaku masih terjadi kesalahan konfigurasi dynamic routing sehingga jaringan yang dibangun belum dapat berkoneksi. Sedangkan pada pelatihan virtual LAN, hampir seluruh peserta merasa bahwa mereka mampu membangun virtual LAN sederhana untuk jaringan suatu kantor. Hasil pemantauan ini menunjukan $83,3 \%$ atau \pm 21 peserta dapat membangun jaringan virtual LAN dan sisanya \pm 4 peserta perlu dibantu oleh pendamping pelatihan.

\section{E. Dokumentasi Kegiatan}

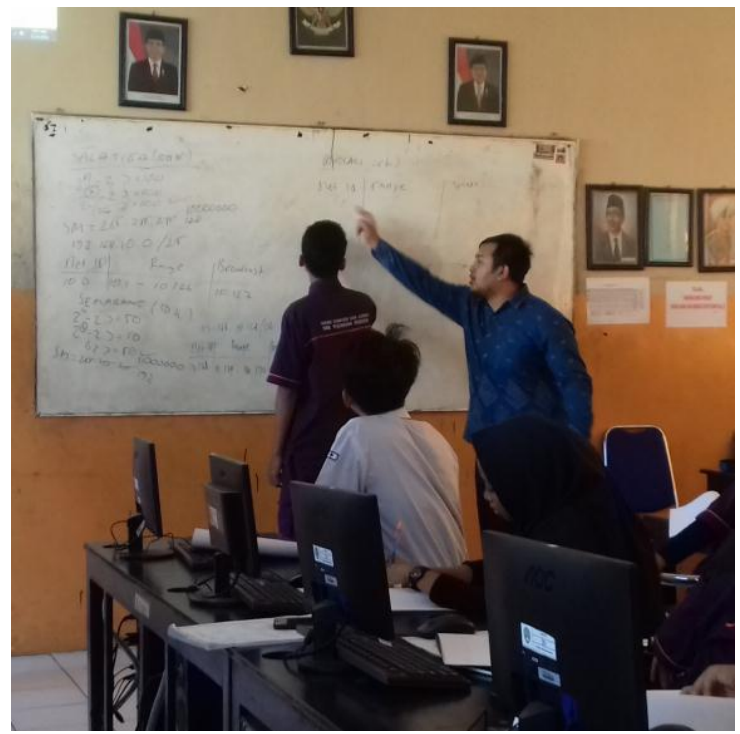

Gambar 4. Keadaan Pengabdian

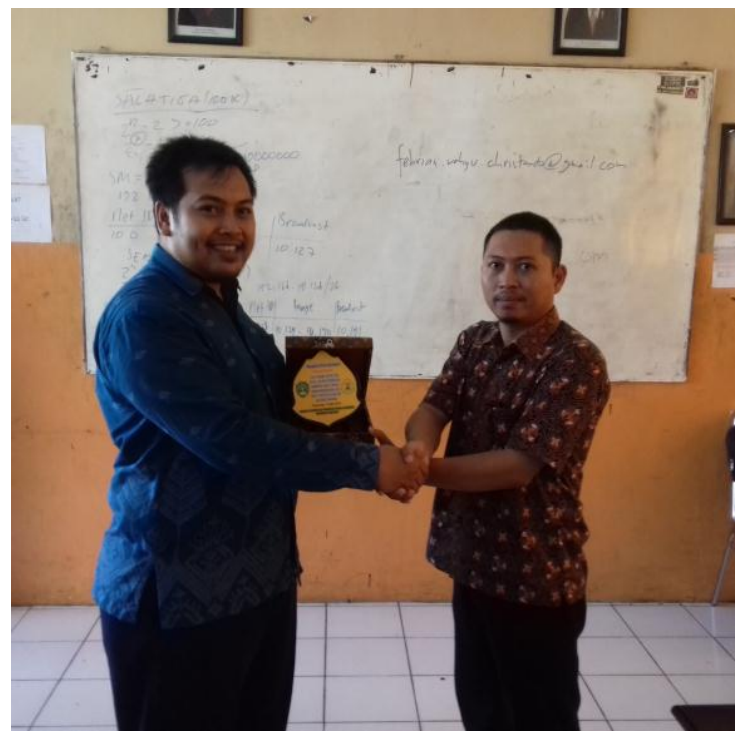

Gambar 5. Penyerahan Kenang-kenangan Kepada Guru SMK Walisongo Semarang

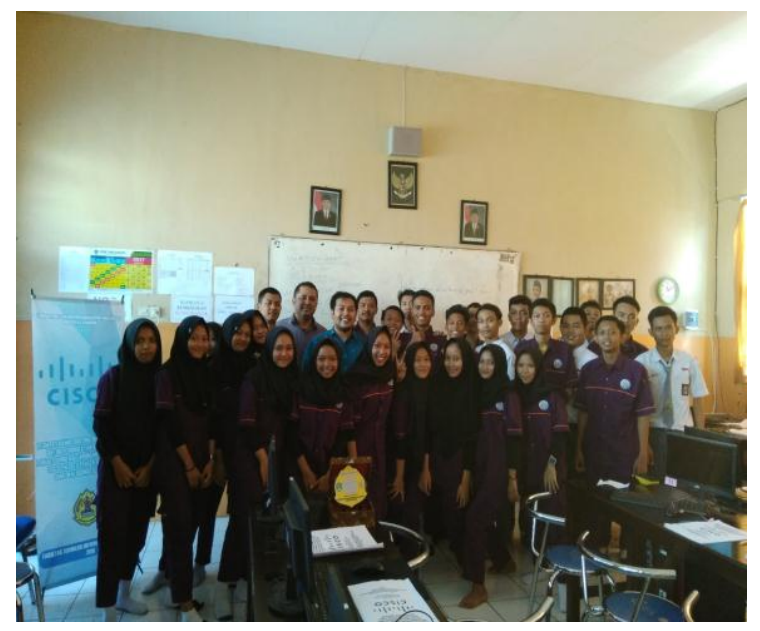

Gambar 6. Foto Bersama dengan Peserta

\section{KESIMPUlan DAN SARAN}

\section{A. Kesimpulan}

Siswa SMK Walisongo Semarang telah mendapatkan pelatihan peningkatan kemampuan jaringan komputer lanjut berbasis Cisco dengan menggunakan perangkat lunak Cisco Packet Tracer. Pelatihan ini mengambil materi tentang perhitungan IP dengan metode VLSM, dynamic routing, dan virtual LAN. Kesimpulan yang dapat ditarik dari pelatihan ini adalah perlunya pemahaman lebih tentang konfigurasi jaringan komputer berbasis Cisco karena sebagian besar SMK yang mempunyai jurusan TKJ (Teknik Komputer Jaringan) hanya mengajarkan jaringan berbasis Mikrotik saja. Pemantauan dari tim pengabdian hal ini masih kurang karena kebutuhan dunia industri sekarang ini tidak hanya cukup dengan konfigurasi jaringan Mikrotik saja. Banyak perusahaan-perusahaan besar menggunakan teknologi Cisco untuk mendukung operasional jaringan komputer mereka.

Dalam pelatihan ini, siswa SMK Walisongo Semarang diberikan materi konfigurasi jaringan Cisco lanjut untuk menambah ilmu menghadapi dunia kerja mendatang. Dari hasil pelatihan ini hampir seluruh peserta pelatihan sepakat bahwa kemampuan mereka dalam membangun jaringan komputer berbasis Cisco menjadi lebih meningkat.

\section{B. Saran}

Dari pelatihan yang telah dilakukan, tim pengabdian dapat memberikan saran yaitu dilakukan beberapa penambahan materi jaringan komputer Cisco dalam kurikulum SMK terutama pada jurusan TKJ (Teknik Komputer Jaringan). Saran berikutnya adalah pelatihan lanjutan dari program pengabdian kepada masyarakat ini tentang konfigurasi keamanan data dan keamanan jaringan menggunakan Cisco.

\section{UCAPAN TERIMAKASIH}

Terimakasih kepada Lembaga Penelitian dan Pengabdian 
kepada Masyarakat (LPPM) Universitas Semarang yang telah mendanai kegiatan PkM ini serta terimakasih kepada mitra kegiatan ini yaitu SMK Walisongo Semarang.

\section{DAFTAR PUSTAKA}

[1] Dewi Y., dkk, "Simulasi Kinerja Routing Protokol Open Shortest Path First (OSPF) dan Enhanced Interior Gateway Routing Protocol (EIGRP) Menggunakan Simulator Jaringan Opnet Modeler v.14.5", Jurusan Teknik Elektro Universitas Brawijaya, Malang.

[2] Christanto, F., W., "Modul Praktikum Manajemen Jaringan", Jurusan Teknologi Informasi, Universitas Semarang, Semarang.

[3] Doro E., "Kajian Algoritma Routing dalam Jaringan Komputer", Jurusan Sistem Informasi, Fakultas Teknologi Informasi, Universitas Kristen Maranatha, Bandung.

[4] Febri U., dkk, "Analisis KInerja Routing Dinamis dengan Teknik RIP (Routing Information Protocol) pada Topologi Ring dalam Jaringan LAN (Local Area Network) Menggunakan Cisco Packet Tracer", Singuda Ensikom, Vol. 7 No.3 Juni 2014, Konsentrasi Teknik Telekomunikasi, Departemen Teknik Elektro, Fakultas Teknik Universitas Sumatera Utara, Medan.

[5] Febrika P., dkk, "Simulasi dan Analisis Dynamic Routing Protocol OSPF dengan Pengalamatan IPv6 pada Perguruan Tinggi Teknorat menggunakan Cisco Packet Tracer", Teknik Informatika, Sekolah Tinggi Manajemen Informatika dan Komputer, Perguruan Tinggi Teknorat, 2015.

[6] Rahmawati, "Konfigurasi Keamanan Jaringan Komputer pada Router dengan Metode ACL's", Jurnal Teknik Komputer AMIK BSI, Vol.1 No.2 Agustus 2015. 